\title{
REVITALISASI HUNIAN KAMPUNG NELAYAN BERBASIS PADA KEHIDUPAN KESEHARIAN NELAYAN
}

\author{
Ryan Hartadi Hiumawan ${ }^{1)}$, Samsu Hendra Siwi ${ }^{2)}$ \\ 1)Program Studi S1 Arsitektur, Fakultas Teknik, Universitas Tarumanagara, ryanhartadi.rh@gmail.com \\ 2) Program Studi S1 Arsitektur, Fakultas Teknik, Universitas Tarumanagara, samsus@ft.untar.ac.id
}

\begin{abstract}
Abstrak
Artikel ini mempelajari tentang revitalisasi kawasan hunian kampung nelayan. Sebagai sebuah kawasan kampung, kampung nelayan memiliki banyak permasalahan mulai dari pemukiman yang tumbuh secara organik, hingga kondisi hunian yang cenderung tidak layak. Dalam proses dan usaha peningkatan kualitas hunian para nelayan, telah dilakukan berbagai usaha mulai dari penyediaan rusun dan lain sebagainya. Namun usaha ini cenderung hanya berfokus pada penyediaan hunian secara massal tanpa memperhatikan karakteristik kehidupan nelayan itu sendiri. Proyek revitalisasi kampung nelayan di kawasan Kalibaru ini dirancang untuk menjadi opsi penyediaan hunian yang lebih layak bagi nelayan dengan tetap memperhatikan karakteristik dan aktivitas sehari-hari nelayan. Selain melakukan penyediaan hunian, proyek ini juga berusaha menghadirkan berbagai program dan fasilitas berdasarkan pada kebutuhan nelayan baik dalam kehidupan sehari hari maupun yang mendukung pekerjaannya, untuk mendapatkan berbagai hal yang sesuai dengan kebutuhan nelayan dalam penelitian ini menggunakan metode kualitatif yang berbasis pada perilaku keseharian nelayan Kalibaru. Proses perancangan pada proyek ini diawali dari perilaku kehidupan nelayan kemudian dieksplorasi lebih dalam dengan menggali lapisan kehidupan nelayan melalui berbagai sumber di internet dan literatur terkait. Hal ini bertujuan agar desain bangunan serta program yang dihasilkan sesuai dengan konteks dan kebutuhan nelayan serta kawasan kampung nelayan. Beberapa program yang coba dihadirkan pada proyek ini seperti pasar ikan, dermaga, pujasera, dan lain sebagainya. Suasana kampung exciting juga berusaha dihadirkan dengan membiarkan sirkulasi vertikal terbuka seolah adalah gang di perkampungan. Sehingga diharapkan Proyek ini dapat menjadi sebuah kawasan kampung vertikal yang nyaman untuk ditinggali dan bersifat lebih liveable dan dapat menjadi sebuah kawasan berhuni yang berkelanjutan.
\end{abstract}

Kata kunci: hunian; kampung nelayan; karakteristik; nelayan; perilaku nelayan.

\begin{abstract}
This article learns about the revitalization of the fishing village residential area. As a village area, fishing villages have many problems ranging from villages that continue to grow organically, to housing conditions that tend to be unfit. In the process of improving the quality of the fishermen's housing, we have been made various efforts, starting from provisioning flats and so on. However, this effort tends to only focus on providing mass residential areas without paying attention to the characteristics of the fishermen. This fishing village revitalization project in Kalibaru Area is designed to be an option in providing more decent residential for fishermen with deep attention to the fishermen's characteristics and daily activities. This projects also providing various programs and facilities based on the fishermen's needs, both their daily and work-related needs, to get various things that suit the needs of fishermen, this research uses qualitative methods based on the daily behavior of fishermen in Kalibaru. The design process of this projects began with the behavior of fishermen's life which next was explored deeper by exploring through various sources from the internet and related literature. It aims to produce buildings and programs under the context and needs of fishermen and the village area
\end{abstract}


itself. Several programs are being tried in this project, such as fish market, dock, food court, and so on. The exciting village atmosphere is also trying to be presented by leaving the vertical circulation open as if it were an alley in the village. This project might build a vertical village area that is more comfortable and liveable, so the village can be a sustainable inhabited area.

Keywords: characteristics; fishermen; fishermen behavior; fishermen's village; residential.

\section{PENDAHULUAN}

\section{Latar Belakang}

Pola hidup nelayan berada di kawasan pesisir mempunyai ciri khusus yang berbeda dengan pola kehidupan non-nelayan. Ciri khusus ini, tidak lepas dari praktek keseharian masyarakatnya yaitu melaut, menjemur dan mengelolah ikan dan hasil tangkapan lainnya, berjualan ikan, memperbaiki jaring dan lain sebagainya. Obyek penelitian ini adalah Kampung Nelayan Kalibaru. Kesan awal pengamatan di Kampung Nelayan Kalibaru terlihat sebuah kawasan pemukiman yang tidak tertata, kumuh, padat dan banyak menghadapi masalah lainnya. Berdasarkan hal tersebut sehingga dirasa perlu dilakukan berbagai usaha untuk memperbaiki dan meningkatkan kualitas hunian nelayan. Berbagai usaha untuk memperbaiki kualitas permukiman nelayan telah dilakukan, seperti penyediaan rusun untuk nelayan di berbagai kawasan termasuk pulau reklamasi (Usmagi, 2020). Namun dalam prosesnya cenderung hanya berfokus pada penyediaan hunian secara massal, tanpa mempertimbangkan aspek lain seperti cara nelayan hidup, keseharian, interaksi sosial dan fenomena fenomena yang terkandung di dalam kampung nelayan exciting. Menciptakan hunian nelayan tanpa mepertimbangkan hal hal tersbut, dan menyeragamkan desain hunian rusun untuk nelayan dengan rusun pada umumnya sama dengan menjauhkan mereka dari kehidupan asli mereka sebagai nelayan. Proyek ini secara khusus berfokus pada usaha penyediaan dan revitalisasi hunian nelayan yang sesuai dengan karakteristik dan cara hidup nelayan itu sendiri.

\section{Rumusan Permasalahan}

Permasalahan pada objek penelitian yaitu Kampung Nelayan Kalibaru, adalah pemukiman yang tumbuh secara organik, tanpa mempertimbangkan instalasi utilitas dan menjadikan kawasan ini rawan terhadap berbagai resiko, seperti kebakaran dan kesulitan pemasangan instalasi air bersih (karena memiliki resiko kebocoran yang tinggi). Disamping itu kurangnya fasilitas penunjang sebuah kampung seperti RPTRA, tempat ibadah, dan fasilitas yang lain, sangat dirasakan oleh masyarakat nelayan. Hal tersebut akan mengurangi kualitas hidup mereka. Oleh karena itu penataan ulang (redesign) permukiman nelayan, berbasis pada perilaku keseharian mereka, menjadi sebuah keharusan.

\section{Tujuan}

Adapun tujuan utama dari proyek ini adalah untuk melakukan redesign pada hunian dan kawasan Kampung Nelayan Kalibaru, dengan berbasis pada kehidupan, keseharian, dan kebutuhan nelayan itu sendiri. Dengan cara menghadirkan berbagai fasilitas bagi kawasan tersebut seperti RPTRA, tempat ibadah, dermaga, pasar ikan dan sebagainya, dan dengan menata kembali kampung sehingga menjadi kawasan yang teratur, sehingga dapat dengan mudah terkoneksi dengan instalasi air baik itu PAM ataupun instalasi air bersih lainnya (dalam proyek ini adalah instalasi pengelolaan air hujan).

\section{KAJIAN LITERATUR}

Proses revitalisasi adalah sebuah usaha untuk membenahi kembali suatu kawasan yang telah mengalami penurunan kualitas lingkungan dalam berbagai lingkup kehidupan seperti ekonomi, 
sosial budaya, makna, citra dan visual kawasan, maka dilakukan intervensi yang bersifat fisik dan non fisik, yang bertujuan untuk memperbaiki kualitas kawasan tersebut (Martokusumo, 2008). Menurut Departemen Kimpraswil (2002), revitalisasi kawasan adalah upaya upaya untuk menghidupkan dan meningkatkan nilai vitalis suatu kawasan yang yang masih mempunyai potensi dan atau mengatur kawasan yang berada pada kondisi yang berantakan (Karta, Tjung, \& Priyendiswara, 2019). Revitalisasi kawasan bertujuan untuk mengembalikan atau menghidupkan kembali kawasan yang tidak berfungsi atau mengalami penurunan fungsi, atau mengembangkan kawasan yang sangat berkembang namun tidak terkendali (Arinta, 2015) nelayan dan lain sebagainya.

Berdasarkan penjabaran diatas, rencana revitalisasi pada kawasan kampung nelayan, dirasa sangat tepat untuk membantu meningkatkan kualitas hidup di kampung nelayan, bukan saja dari aspek fisik, tetapi juga aspek non fisik yang terkandung di dalam kawasan kampung nelayan. Adapun beberapa pendekatan dalam melakukan revitalisasi adalah sebagai berikut (Hizmiakanza, 2018):

Intervensi Fisik

Pendekatan ini merupakan perbaikan faktor fisik lingkungan termasuk didalamnya adalah bangunan, tata dan ruang terbuka hijau kawasan. Pada proses ini erat kaitannya dengan pembentukan citra sebuah kawasan, sehingga tahapan ini bertujuan untuk meningkatkan kualitas visual kawasan.

Rehabilitasi Ekonomi

Pendekatan ini berupa perbaikan fasilitas fisik jangka pendek yang bertujuan agar dapat mewadahi kegiatan ekonomi, baik formal maupun informal di kawasan tersebut. Pada tahap ini juga perlu dikembangkan aktivitas ekonomi dan sosial baru untuk meningkatkan nilai dari kawasan.

Revitalisasi Sosial

Pendekatan ini bertujuan untuk mengembangkan institusi yang baik agar berdampak positif dan dapat meningkatkan dinamika dalam kehidupan sosial masyarakat. Agar revitalisasi ini tidak sekedar menciptakan keindahan pada lingkungan fisik saja.

Secara Fisik dan Fisiologis

Terdapat beberapa faktor yang membuat suatu kawasan perlu dilakukan proses revitalisasi. Adapun beberapa faktor tersebut antara lain tingkat vitalitas pada kawasan yang meliputi tingkat kepadatan penduduk, rata rata pendapatan masyarakatnya, tingkat Kesehatan, keamanan dan tingkat kriminal. secara fisik dan fisiologis (Nur'Aini, Triharti, \& Rahman, 2015).

Karena secara spesifik, proyek ini mengambil objek kampung nelayan, maka perlu mengetahui tentang apa itu kampung nelayan. Kampung nelayan dapat diartikan sebagai sebuah kawasan hunian dimana penghuninya memiliki pekerjaan yang sama yaitu bekerja dibidang usaha perikanan, dengan kondisi kawasan perkampungan kurang baik dan terdiri dari 2 lapisan sosial yaitu juragan dan nelayan kecil. Ada 2 faktor yang sangat mempengaruhi kehidupan di kawasan nelayan yaitu musi faktor alam dan ekonomi (Rahardjo, 2014). Sebagai sebuah tempat berhuni nelayan, kampung nelayan juga memiliki beberapa pola, Adapun pola pola perkampungan nelayan adalah (Kostof, 1983):

- Pola Cluster, rumah atau unit hunian memusat pada ruang penting seperti penjemuran ikan fasilitas umum, mushola atau masjid dan lain sebagainya.

- Pola Linear, rumah bersusun secara linear dan terdapat peletakkan ruang penting seperti dermaga, tempat penjemuran dll, di antara rumah atau unit hunian.

\section{Arsitektur Perilaku}


Untuk dapat melakukan revitalisasi pada sebuah Kampung Nelayan secara tepat, maka digunakan pendekatan arsitektur perilaku untuk dapat memahami perilaku perilaku masyarakat di Kampung Nelayan. Arsitektur perilaku pertama kali ada pada tahun 1950, dimana arsitek perilaku dalam proses mendesainnya selalu mempertimbangkan perilaku manusia dikarenakan sebuah bangunan berfungsi untuk mewadahi aktivitas manusia sebagai penggunanya dan antara bangunan dan perilaku pengguna tidak bisa dipisahkan (Agustina, Purwantiasning, \& Prayogi, 2018). Tujuan utama dari arsitektur perilaku adalah dapat mewadahi berbagai kegiatan masyarakat di suatu kawasan pada satu wadah. (Tandali, 2011)

Untuk memahami penerapan arsitektur perilaku, maka perlu juga memahami apa yang dikategorikan sebagai perilaku. Adapun yang termasuk dalam perilaku dalam kontek arsitek perilaku adalah sebagai berikut:

- Perilaku yang tampak dengan mata seperti makan, memasak, anak anak bermain, interaksi sosial antar tetangga dan lain sebagainya.

- Perilaku yang tidak tampak dengan mata seperti pola pikir masyarakat, motivasi kerja, imajinasi masyarakat dan lain sebagainya.

- Aksi/kegiatan masyarakatnya

Berdasarkan deskripsi diatas konsep arsitektur perilaku sangat tepat digunakan untuk melakukan proses redesign pada kawasan Kampung Nelayan Kalibaru, yang memiliki berbagai perilaku yang unik. Adapun prinsip prinsip dari arsitektur perilaku adalah (Agustina, Purwantiasning, \& Prayogi, 2018) :

- Bangunan harus dapat mampu berkomunikasi dengan manusia dan harus dapat dipahami oleh pemakainya baik secara indrawi ataupun imajinasi penggunanya.

- Mewadahi aktivitas penghuninya dengan nyaman secara fisik dan psikis dan menyenangkan. secara fisik dan fisiologis.

- Memperhatikan kondisi dan perilaku dari pengguna bangunan

\section{Aktivitas Kampung Nelayan}

Pola aktivitas pada perkampungan nelayan, dikelompokkan berdasarkan jenis aktivitasnya yaitu penangkapan dan penjualan ikan, dan penjemuran ikan asin. Pola aktivitas yang dimaksudkan pada sub bab ini merupakan aktivitas aktivitas yang ada di kawasan Kampung Nelayan Kalibaru, Cilincing. itu juga alur aktivitas juga dibuat berdasarkan pembagian subjek atau pelaku utamanya, yang dapat dilihat pada gambar gambar berikut:

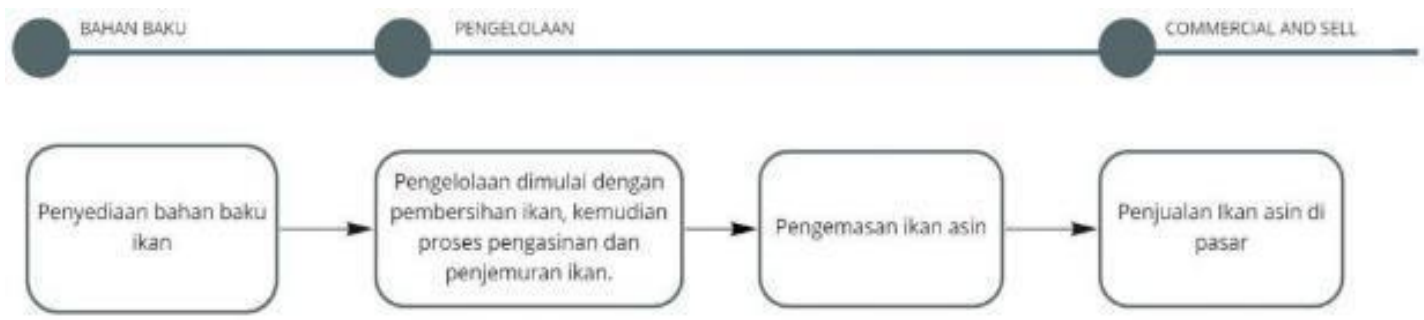

Gambar 1: Skema Alur Aktivitas Penangkapan Hingga Penjualan Ikan Sumber: Penulis, 2021 


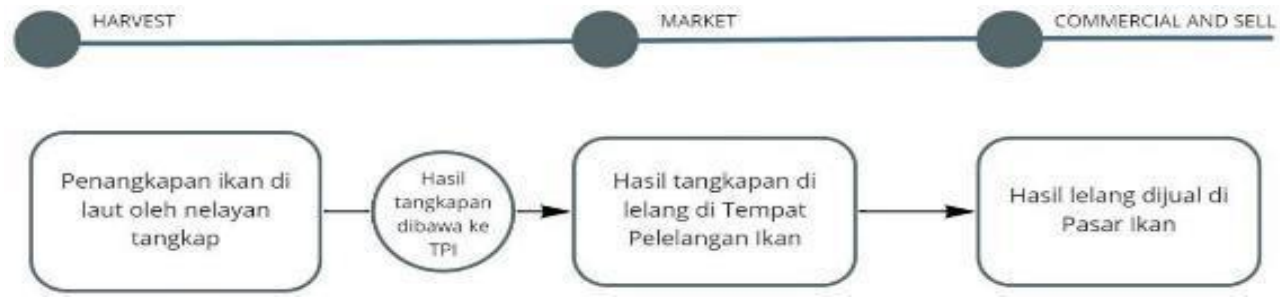

Gambar 2: Skema Aktivitas Penangkapan Ikan

Sumber: Penulis, 2021

Selain aktivitas aktivitas yang ada pada skema skema di atas, juga terdapat beberapa aktivitas yang umum dilakukan oleh penduduk di kawasan Kampung Nelayan. Seperti pada kaum ibuibu yang dapat juga bekerja sebagai pedagang ikan di pasar, pemilik warung, dan buruh. Secara general dan di Kawasan Kampung Nelayan dapat dilihat pada gambar 3, dimana pada gambar 3 skema aktivitas di kelompokan berdasarkan subjek atau pelaku.

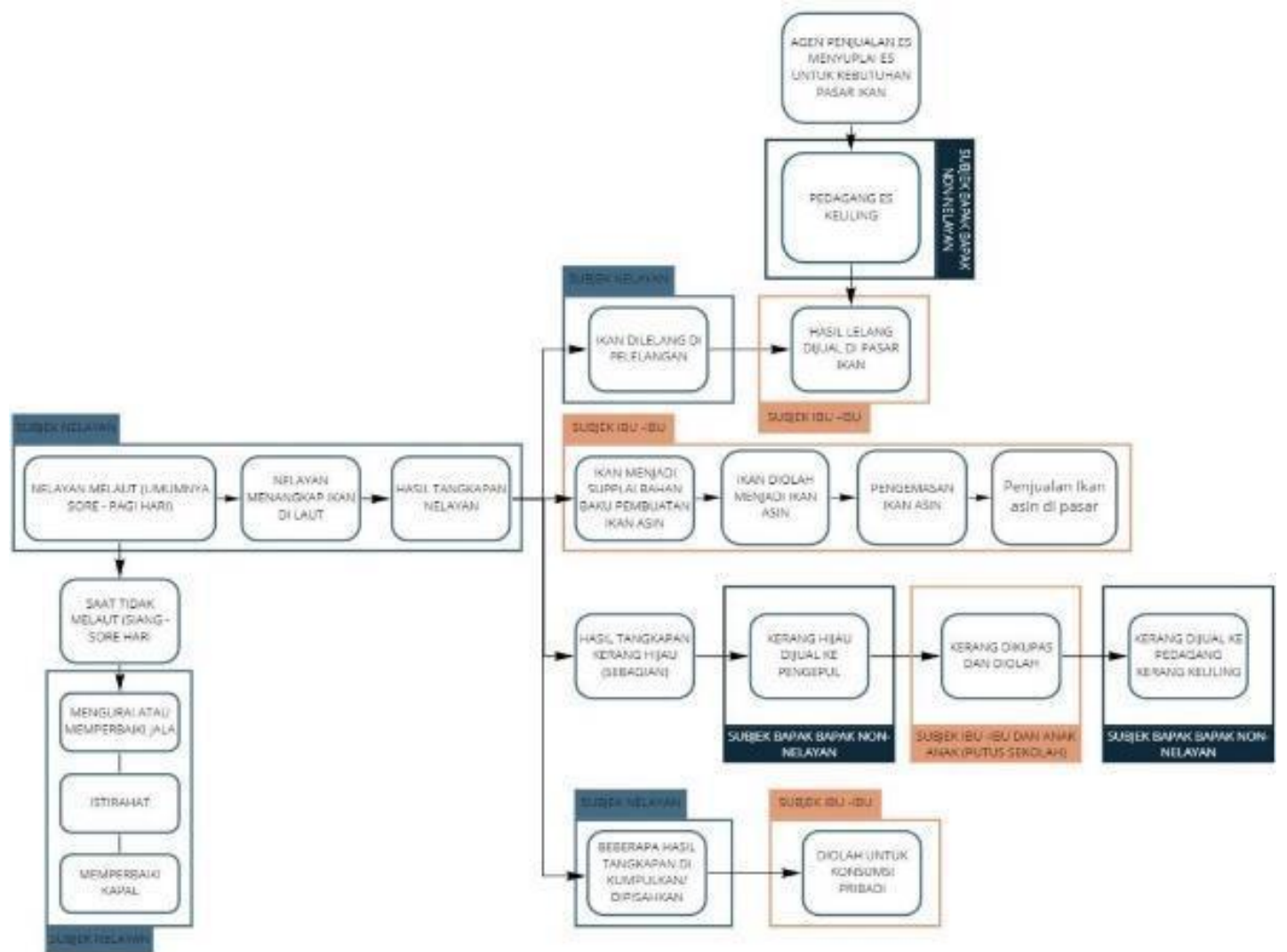

Gambar 3. Skema Aktivitas di Kampung Nelayan Berdasarkan Subjek Pelakunya Sumber: Penulis, 2021

\section{METODE}

Penelitian ini memakai metode kualitatif, berbasis pada fenomena keseharian nelayan Kalibaru. Pengambilan data dilakukan dengan observasi langsung dan data sekunder dari beberapa sumber seperti e-book, e-journal, artikel dan video berita, dan lain sebagainya.

Proses pengumpulan data, terbagi menjadi 2 tahapan. Tahapan pertama adalah studi literatur yang bertujuan untuk menemukan teori untuk dasar pemikiran dan juga sebagai konsep awal untuk mengetahui karakteristik dan fabric kawasan, serta mengetahui standar standar terkait perancangan hunian dan proses revitalisasi. Tahap kedua adalah dengan pengamatan fenomena fenomena yang ada di dalam kawasan kampung nelayan eksisting. Pada tahap ini 
karena keterbatasan di masa pandemi, maka kumpulan fenomena fenomena didapat dari berbagai sumber seperti artikel berita, jurnal, serta berbagai video liputan, pada Kawasan kampung nelayan.

Setelah tahap pengumpulan data, maka dalam proses mendesain menggunakan pendekatan perilaku masyarakat di kawasan Kampung Nelayan Kalibaru. Pendekatan dimulai dengan mengamati perilaku masyarakat di dalam rumah masing masing, kemudian mengamati perilaku di masyarakat di dalam kawasan kampung, dan termasuk di dalamnya adalah cara berinteraksi sosial masyarakatnya. Adapun beberapa perilaku masyarakat yang berhasil dikumpulkan dan respon yang diambil dan diterapkan pada desain dapat dilihat pada kolasa gambar sebagai berikut:

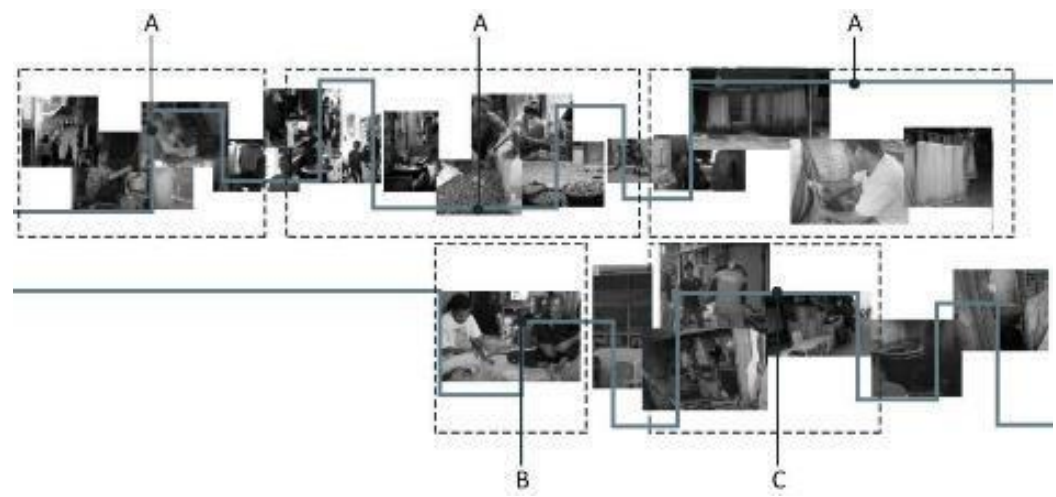

Gambar 4. Kolase Fenomena yang Berhasil ditemukan di Kampung Nelayan Kalibaru Sumber: Berbagai Sumber dan Literatur Online Kemudian di Kolase Oleh Penulis, 2021

A. Dilakukannya berbagai aktivitas yang dilakukan di teras rumah seperti gang atau teras di perkampungan nelayan, seperti menjemur pakaian, mencuci, dan menyimpan barang, kemudian teras rumah juga digunakan untuk menjemur ikan bersama tetangga, mengupas kerang, memperbaiki dan menjemur jala atau sekedar berkumpul dengan tetangga. Berdasarkan fenomena tersebut, dapat dikatakan teras rumah menjadi memiliki nilai lebih dibandingkan dengan hanya sebuah ruang perantara atau penghubung antara rumah. Hal ini direspon dengan mendesain koridor antar unit hunian dengan lebar sehingga koridor dapat dimanfaatkan sebagai sebuah teras komunal bersama, untuk dapat melakukan berbagai aktivitas tersebut.

B. Ruang bagian dalam rumah pada umumnya hanya terdiri dari kamar, kamar mandi, dan ruang tengah atau ruang keluarga, kegiatan lain seperti makan tidak membutuhkan tempat makan khusus. Kegiatan makan umumnya dilakukan di ruang keluarga/ Tv, hal ini direspon dengan menghilangkan program ruang makan pada tiap unit rumah, sehingga ruang dalam rumah hanya terdiri dari ruang yang dibutuhkan.

C. Terdapat rumah rumah yang bagian depannya dijadikan sebuah warung, hal ini dilakukan untuk membantu meningkatkan ekonomi keluarga. Hal ini direspon dengan menyediakan unit unit hunian yang dilengkapi dengan ruang untuk warung.

Berdasarkan deskripsi diatas, dengan memadukan data hasil literatur (standar, standar program, standar SNI) dan melakukan proses desain dengan menggunakan pendekatan perilaku masyarakatnya diharapkan dapat membuat sebuah kawasan hunian yang sesuai dengan kebiasaan hidup masyarakat Kawasan Kampung Nelayan Kalibaru.

\section{DISKUSI DAN HASIL}

\section{Kondisi Kampung Exciting (Before Re-design)}

Status Kepemilikan Tanah. Secara garis besar, kebanyakan pemukiman yang berdiri di kawasan 
Kalibaru, Cilincing berdiri di atas lahan milik negara. Adapun persentase kepemilikan lahan pada kawasan tersebut adalah sebagai berikut tanah negara: $233.20 \mathrm{Ha}$ dan tanah hak milik: 13.50 Ha (Marihot, 2017).

Tidak Ada Batas Perkembangan Permukiman Ke Arah Laut. Terus bertumbuhnya jumlah penduduk di kawasan Kampung Nelayan Cilincing Kalibaru, membuat jumlah rumah terus bertambah. Perkembangan rumah di kawasan ini menempati ruang ruang di atas air (terapung).

Kurangnya fasilitas memadai. Kawasan Kampung Nelayan Kalibaru mengalami kekurangan fasilitas yang memadai seperti tidak tersedianya tempat ibadah (mushola), ruang bermain anak dan ruang terbuka (lapangan terbuka). Selain itu Kawasan Kampung Nelayan Kalibaru juga minim akan fasilitas yang terkait dengan utilitas terutama instalasi penyalur air bersih, kawasan ini juga belum secara menyeluruh teraliri oleh PAM dan tanah hak milik: 13.50 (Pemprov DKI Jakarta, 2017).

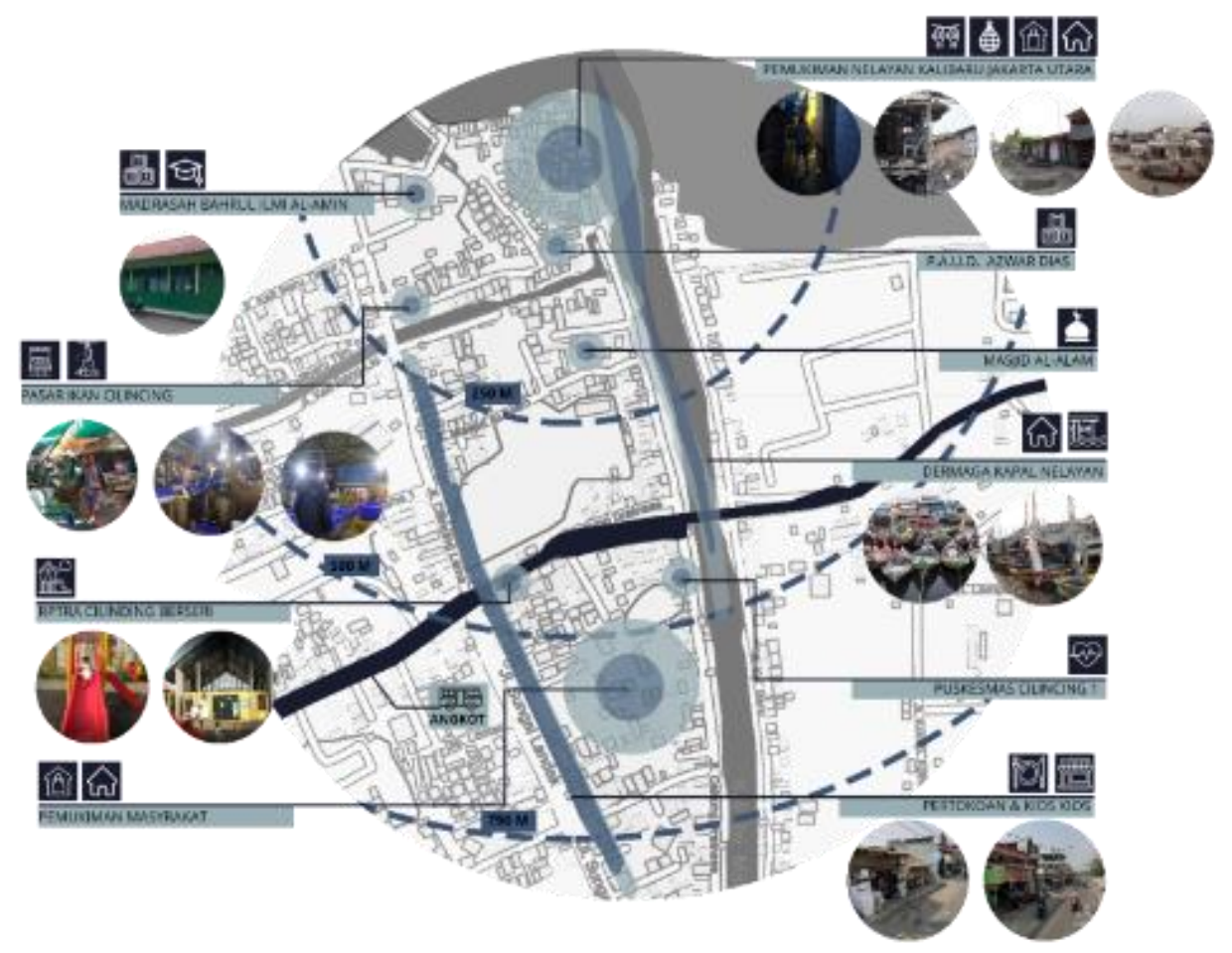

Gambar 5. Mapping Fasilitas di Kawasan Kalibaru Sumber: Penulis, 2021

Kepadatan bangunan tinggi. Secara menyeluruh Kelurahan Kalibaru, memiliki kepadatan penduduk sebesar 29.155 jiwa per kilometer persegi (BPS Jakarta Utara, 2019). Padatnya jumlah penduduk di Kampung Nelayan Kalibaru, menyebabkan kepadatan bangunan juga terus meningkat baik di daratan maupun di atas air, dan pola bangunan yang tidak teratur membuat kepadatan bangunan semakin tidak terkendali.

Sumber air bersih hunian. Kawasan Kawasan Kampung Nelayan, belum secara menyeluruh teraliri oleh instalasi air PAM (PTSP DKI Jakarta, 2017). Hunian di kawasan kampung nelayan, masih bergantung pada pedagang air keliling, mobil air bersih atau dengan air kemasan.

Program ruang pada hunian. Pada rumah rumah atau hunian eksisting hanya terdapat ruang keluarga,kamar tidur, toilet dan dapur (pada banyak rumah,dapur terdapat pada bagian depan rumah), kemudian juga terdapat sebuah teras rumah yang digunakan untuk berbagai aktivitas (menjemur ikan, menyiangi ikan, dll). 
Material Bangunan dan Kondisi Rumah. Kondisi hunian di kawasan Kampung Nelayan Kalibaru, cenderung kumuh dan tidak terawat. Bukan hanya kondisi rumah melainkan juga kondisi berbagai fasilitas penunjang di kawasan tersebut, seperti dermaga yang dibangun dengan konstruksi seadanya, kondisi pasar yang sudah tidak memadai dan lain sebagainya. Material bangunan yang banyak digunakan pada rumah rumah di kawasan ini adalah bambu, asbes, anyaman bambu, dan beberpa rumah menggunakan dinding batako. Kondisi Kampung Nelayan Kalibaru dapat dilihat pada beberapa foto berikut:
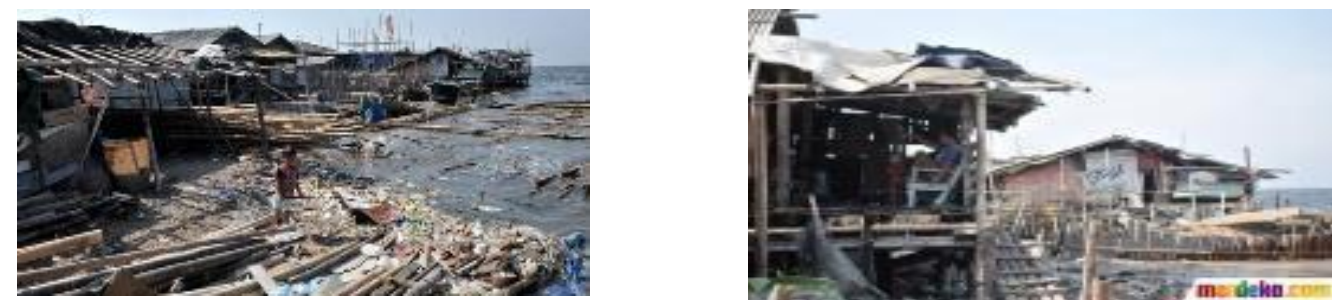

Gambar 6. Kondisi Hunian di Kampung Nelayan Kalibaru Sumber: https://www.merdeka.com/, 2021
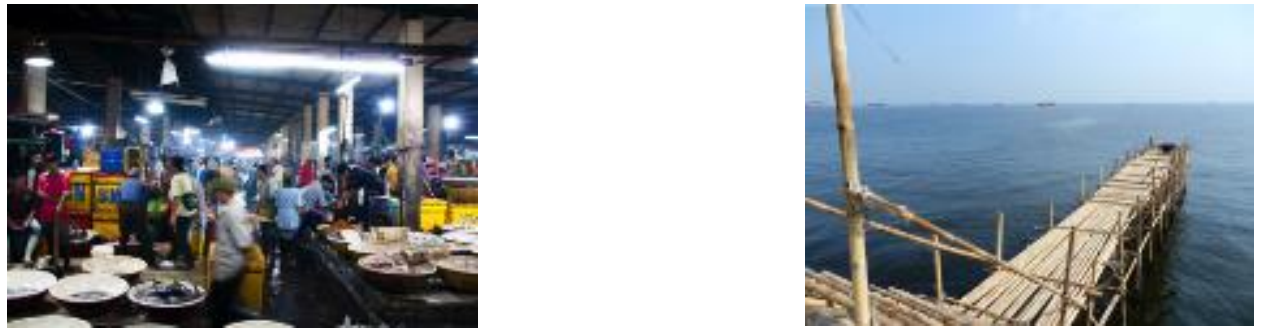

Gambar 7: Kondisi Eksisting Pasar Ikan dan Dermaga di Kawasan Kalibaru Sumber: https://www.flokq.com/blog/id/pasar-ikan-jakarta,

https://bersapedahan.wordpress.com/2018/08/06/berjalan-jalan-ke-pantai-cilincing-kampung-nelayanjakarta/, 2021

\section{Design Unit Hunian}

Design Hunian dibuat dengan konsep modular, yang terinspirasi dari konsep hunian RISHA (Melisa, 2020), dengan sedikit modifikasi pada ukuran modul agar lebih efektif dan sesuai dengan aktivitas nelayan. Konsep modular dipilih agar menciptakan hunian hunian yang lebih terjangkau dan murah bagi nelayan. Hunian terdiri dari $2-3$ modul hunian dan $1-2$ model teras komunal dengan ukuran tiap modul adalah $4 \times 4 \times 4 \mathrm{~m}$. Adapun penerapannya pada unit hunian adalah sebagai berikut:

\section{Desain Hunian A}

Merupakan desain unit hunian yang memiliki 2 lantai. Lantai 1 terdiri dari 4 modul teras yang digunakan sebagai area warung, teras, toilet dan memasak. Dan lantai 2 terdiri dari 3 modul rumah yang digunakan sebagai 3 kamar tidur dan 1 ruang keluarga. 


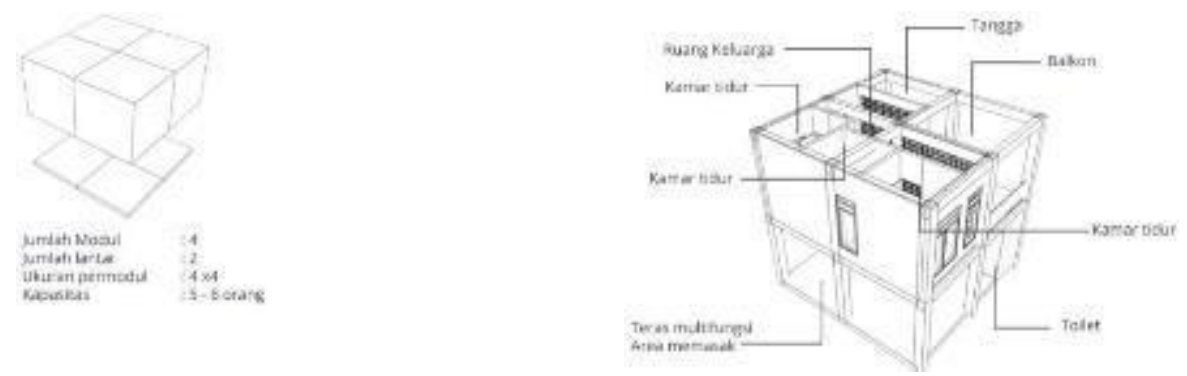

Gambar 8 Design Unit Hunian Tipe A

Sumber: Penulis, 2021

Desain Hunian B

Merupakan desain unit hunian yang terdiri dari 2 modul hunian yang digunakan sebagai 2 kamar tidur, 1 kamar mandi, 1 ruang keluarga dan 2 modul teras yang digunakan sebagai area memasak, teras, dan dapat dikembangkan menjadi bale atau tempat duduk duduk.
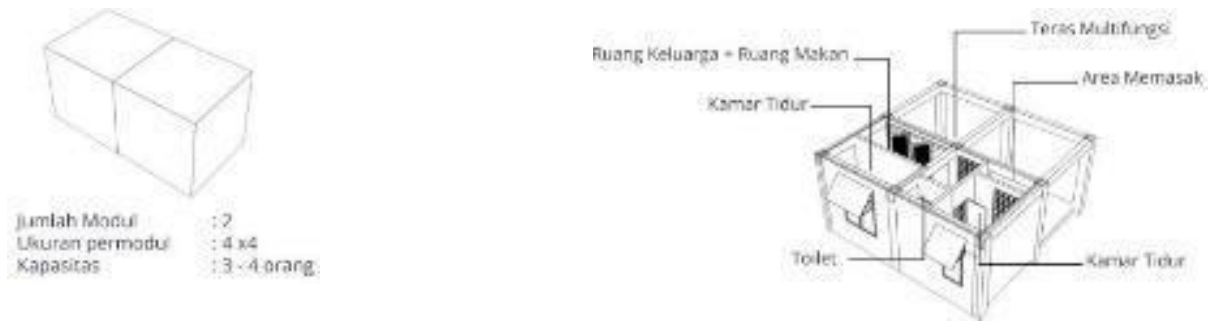

Gambar 9. Design Unit Hunian Tipe B

Sumber: Penulis, 2021

Desain Hunian C

Merupakan desain unit hunian yang terdiri dari 3 modul hunian yang digunakan sebagai 2 kamar tidur, 1 kamar mandi, 1 ruang keluarga, 1 ruang untuk warung dan 1 modul teras yang digunakan sebagai area memasak, teras, dan dapat dikembangkan menjadi bale atau tempat duduk duduk.
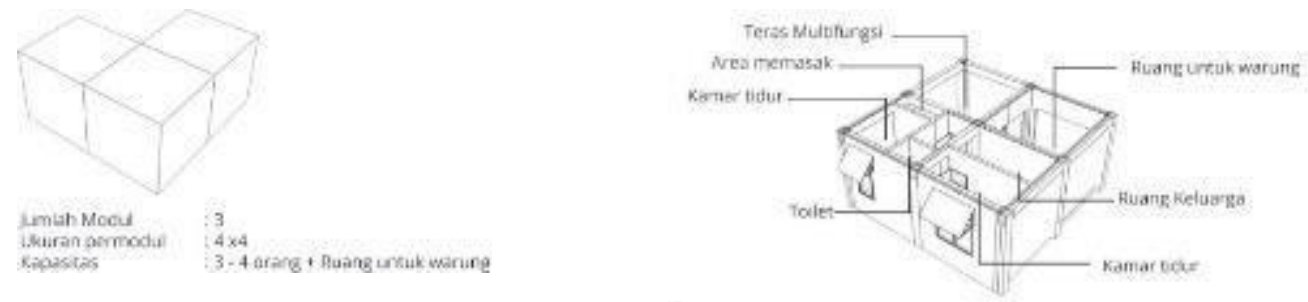

Gambar 10: Design Hunian Tipe C

Sumber: Penulis, 2021

Selain konsep modular, pada desain fasad hunian dilengkapi dengan model pintu lipat yang dapat dibuka dengan lebar serta façade beton roster untuk merespon aktivitas nelayan yang cenderung bersifat bebas dan banyaknya aktivitas yang dilakukan di teras dan agar dapat memasukan cahaya dan udara alami kedalam unit hunian secara maksimal.

\section{Desain Massa Hunian}

Secara menyeluruh desain massa hunian menggunakan pola cluster dimana terdapat area 
penting pada bagian tengah maka bangunan (Kostof, 1983), dimana ruang penting yang dimaksud adalah area penjemuran ikan (dapat dilihat pada gambar 8 ).

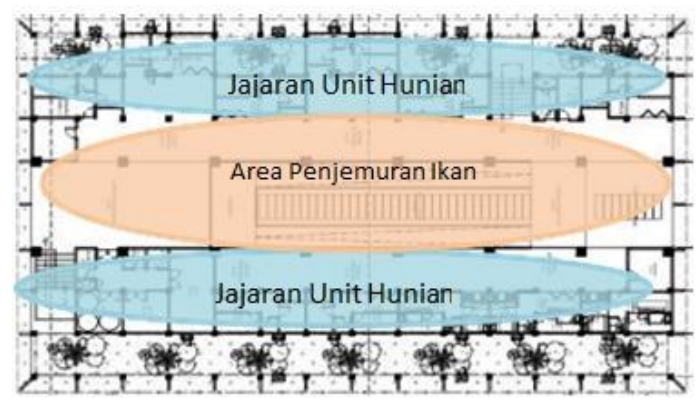

Gambar 11. Gambar Pola Tata Letak Unit Hunian dengan Area Jemur Ikan Sumber: Penulis, 2021

Melihat pentingnya nilai sebuah teras rumah pada kawasan kampung nelayan, maka pada desain kampung susun ini menghadirkan teras yang dilakukan dengan cara menjadikan koridor penghubung antar unit unit hunian sebagai sebuah teras komunal. Koridor dibuat dengan lebar terkecil 4 meter, dan pada beberapa titik disebut dengan lebar 8 meter. Teras komunal ini dibuat dengan menyerupai sebuah arcade, agar cahaya dan pengudaraan alami tetap dapat masuk secara maksimal, sehingga tetap nyaman saat beraktivitas di teras komunal tersebut.

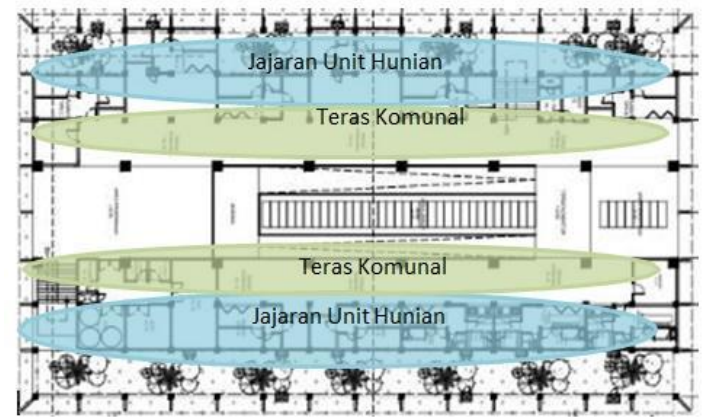

Gambar 12. Pola Tata Letak Hunian dengan Teras Komunal Sumber: Penulis, 2021

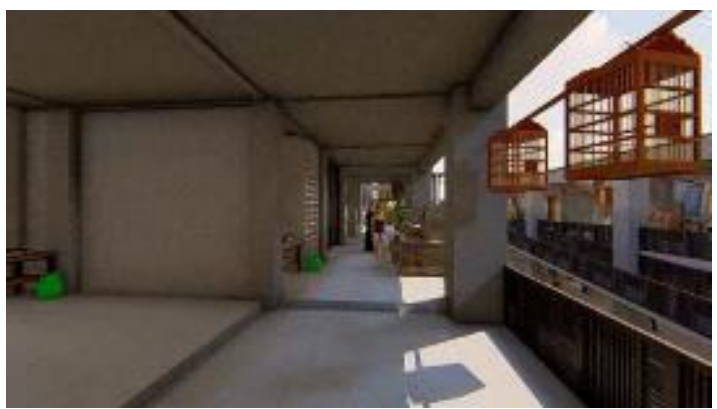

Gambar 13. Konsep Arcade Pada Teras Komunal Sumber: Penulis, 2021

Ramp digunakan sebagai sirkulasi vertikal utama pada masa hunian dan dibuat tanpa atap agar dapat terkena hujan dan panas secara langsung, dengan tujuan untuk mendapatkan kesan sebuah gang di perkampungan, dengan penggunaan ramp ini diharapkan agar penghuni tidak merasakan sedang berjalan naik , melainkan sedang menyusuri gang di perkampungan. 


\section{Penyediaan Air untuk Kawasan}

Salah satu permasalahan pada hunian di kawasan Kampung Nelayan Kalibaru adalah tidak tersedianya sumber air bersih. Pada kondisi eksisting penyediaan air mengandalkan pedagang air keliling, mobil mobil air isi ulang dan air kemasan. Sebagai respon untuk masalah tersebut, pada proses redesign kawasan Kampung Nelayan Kalibaru, dihubungkan dengan instalasi air PAM sebagai sumber utama air di kawasan ini. Selain itu, kawasan ini juga melakukan proses rainwater harvesting yang juga digunakan sebagai sumber air bersih. Proses rainwater harvesting dilakukan oleh roof garden dan juga desain kanopi yang melebar di bagian atas. Adapun skema rain water harvesting pada proyek ini adalah sebagai berikut

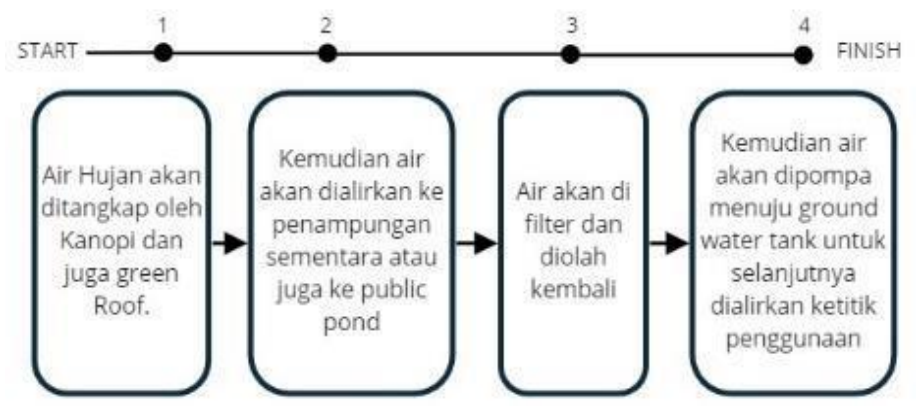

Gambar 14. Skema Rainwater Harvesting Kawasan

Sumber: Penulis, 2021

\section{Tapak}

Tapak terpilih berada di kawasan Kampung Nelayan Kalibaru, Cilincing Jakarta Utara. Tapak ini dipilih karena memenuhi beberapa kriteria yang menjadi pertimbangan antara lain, kedekatan tapak dengan kawasan eksisting kampung nelayan, dan berada di kawasan pesisir sehingga dekat dengan laut yang merupakan mata pencaharian utama nelayan.

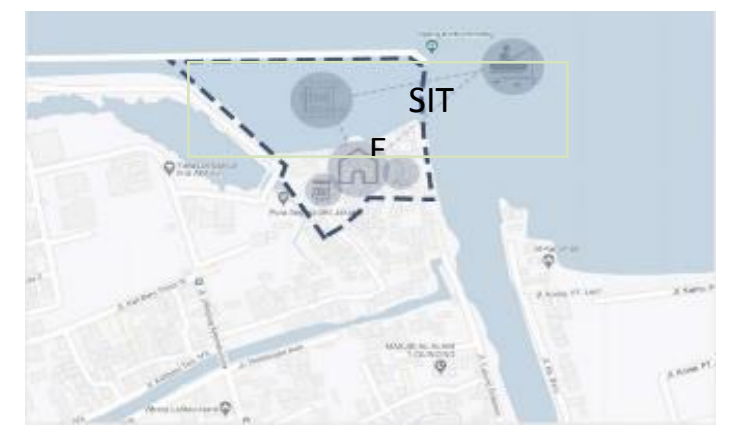

Gambar 15. Tapak Terpilih

Sumber: google.co.id/maps

Tapak terbagi menjadi 2 area yaitu daratan dan kawasan perairan, kawasan perairan sendiri dipilih untuk merespon adanya fenomena fenomena rumah yang terapung di kawasan kampung nelayan Kalibaru. Selain itu juga kawasan perairan dimanfaatkan untuk fasilitas fasilitas ruang penting.

\section{Rancangan Kawasan (Master Plan)}

Selain menciptakan design unit hunian yang lebih sesuai dengan aktivitas keseharian nelayan, mulai dari program ruang dalam unit hunian, menghadirkan teras penjemuran ikan di tengah massa hunian, hingga menjadikan koridor antar unit menjadi sebuah teras komunal. 
Mengkoneksikan kawasan dengan aliran PAM dan juga membuat rain water harvesting pada kawasan, strategi lain juga diterapkan pada perancangan master plan atau desain kawasan untuk menghadirkan sebuah kawasan hunian yang lebih sesuai dengan karakter dan aktivitas nelayan. Pada kawasan Kampung Susun Nelayan dihadirkan beberapa program program lain seperti pasar dan pelelangan ikan, food court, kawasan dermaga, event lawn, RPTRA, Musholla, promenade dan taman bakau. Pasar dan pelelangan ikan mewadahi kegiatan jual beli serta pelelangan hasil tangkapan nelayan dan memberi wadah tempat berjualan bagi keluarga nelayan yang berprofesi sebagai pedagang ikan. Food court merupakan program yang dihadirkan sebagai program baru yang bertujuan untuk meningkatkan ekonomi keluarga nelayan. Kawasan dermaga mewadahi kegiatan berlabuh kapal nelayan, parkir kapal, dan perbaikan kapal oleh nelayan. Event lawn, RPTRA dan Musholla dihadirkan sebagai fasilitas kampung untuk mewadahi kegiatan yang bersifat bersama sama, aktivitas bermain anak dan kegiatan keagamaan. Promenade dihadirkan sebagai sebuah area terbuka yang netral, dan dapat menjadi sebuah daya tarik bagi pengunjung yang datang ke kawasan tersebut, dan merupakan respon dari keberadaan kawasan tepian air. Taman bakau merupakan program yang dihadirkan sebagai usaha untuk memperbaiki ekosistem air di kawasan kampung tersebut.
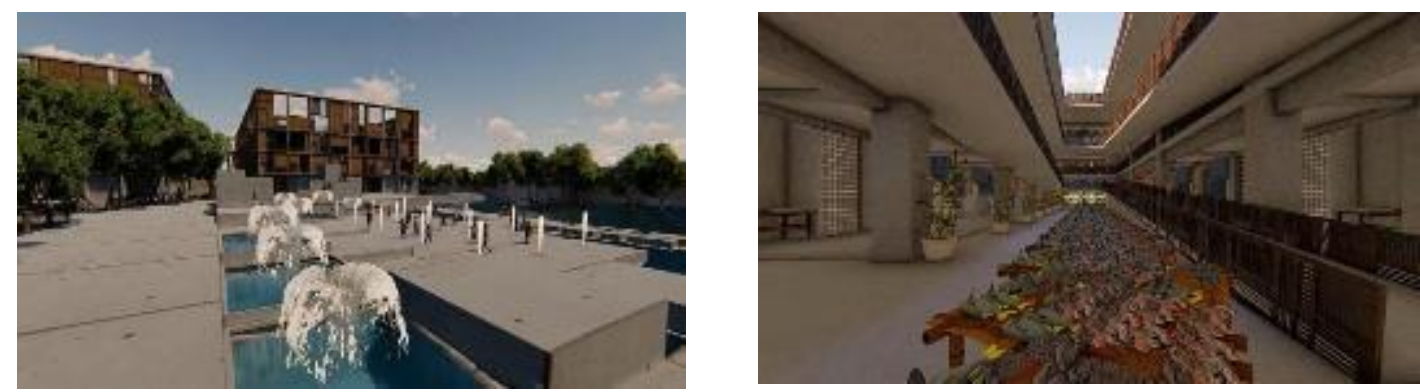

Gambar 16. Area RPTRA dan Area Penjemuran Ikan Komunal di Kawasan Kampung Nelayan Sumber: Penulis, 2021
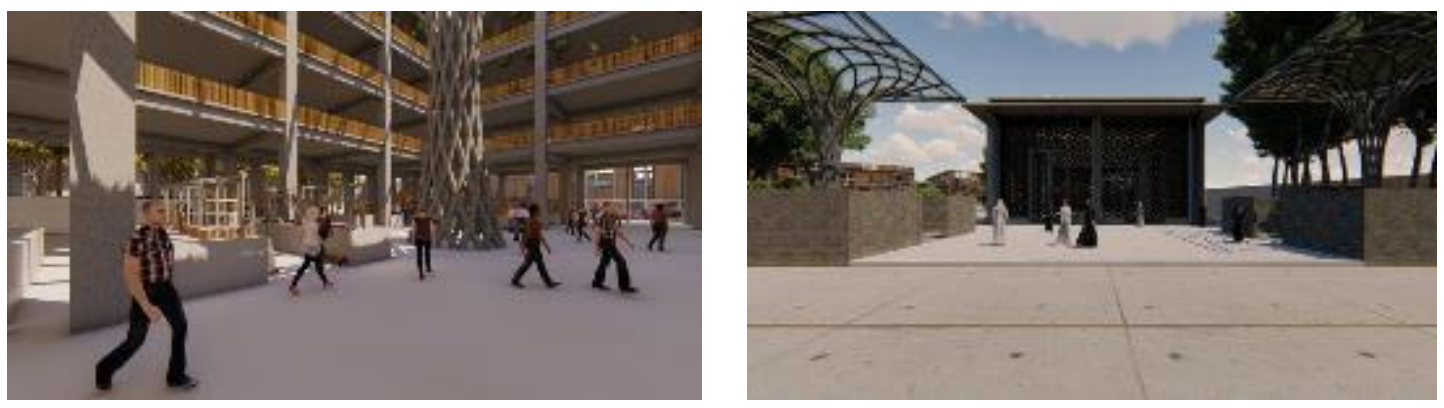

Gambar 17. Gambar Suasana Pasar Ikan dan Bangunan Musholla Sumber: Penulis, 2021 


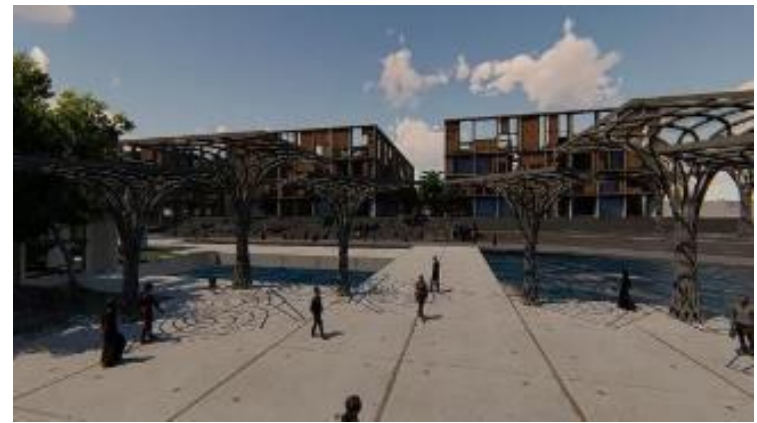

Gambar 18. Gambar Suasana Event Lawn Kawasan Sumber: Penulis, 2021

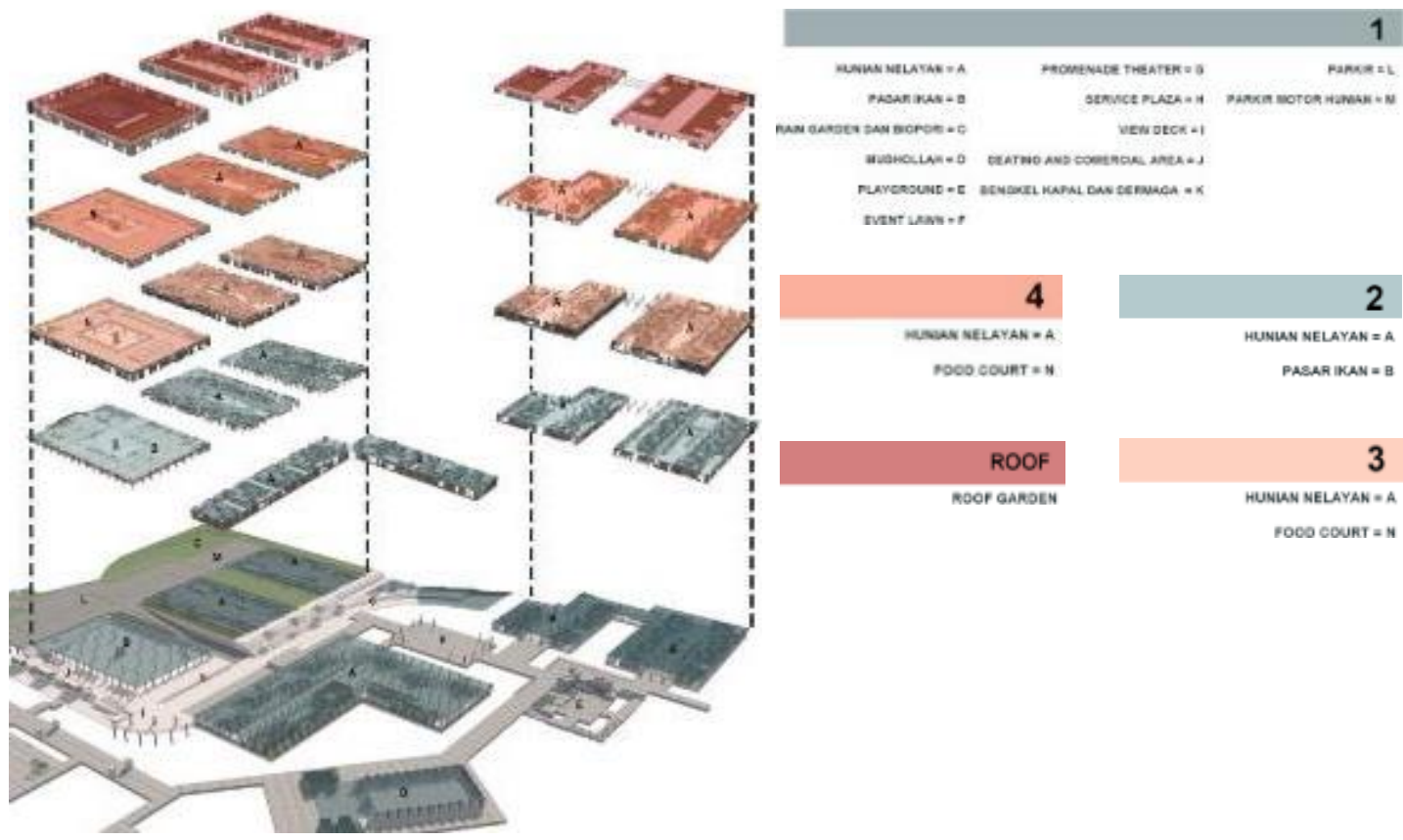

Gambar 19. Program Pada Kawasan

Sumber: Penulis, 2021

Berdasarkan pembahasan hasil perancangan diatas, berikut dilampirkan tabel hasil perbandingan antara kondisi sebelum dan sesudah kawasan di redesign.

Tabel 1. Tabel Perbandingan Sebelum dan Sesudah Kawasan di Revitalisasi

\begin{tabular}{|c|c|c|}
\hline Parameter & Sebelum & Sesudah \\
\hline $\begin{array}{l}\text { Material Bangunan } \\
\text { Hunian }\end{array}$ & $\begin{array}{l}\text { Bambu, anyaman bambu, asbes, dinding } \\
\text { bata (pada beberapa rumah, kayu, Terpal }\end{array}$ & $\begin{array}{l}\text { Beton exposed, kayu, recycled asbes, floating } \\
\text { concrete, roster beton }\end{array}$ \\
\hline $\begin{array}{l}\text { Program ruang } \\
\text { hunian }\end{array}$ & $\begin{array}{l}\text { Di rumah eksisting hanya terdapat ruang } \\
\text { tengah, kamar, toilet, dapur dan teras }\end{array}$ & $\begin{array}{l}\text { Program ruang rumah mengadaptasi program } \\
\text { ruang yang ada pada rumah eksisting. }\end{array}$ \\
\hline Sumber air bersih & $\begin{array}{l}\text { Bergantung pada pedagang air keliling atau } \\
\text { mobil air bersih dan atau air kemasan }\end{array}$ & $\begin{array}{l}\text { Sumber air berasal dari instalasi PAM dan } \\
\text { pengelolaan air hujan yang dilakukan di } \\
\text { kawasan kampung }\end{array}$ \\
\hline \multicolumn{3}{|c|}{ Ketersediaan Berbagai Fasilitas } \\
\hline Dermaga & $\begin{array}{l}\text { Tersedia, dengan konstruksi dan material } \\
\text { bambu }\end{array}$ & $\begin{array}{l}\text { Diperbaiki dan di tata ulang. Desain dermaga } \\
\text { menggunakan konstruksi floating concrete }\end{array}$ \\
\hline Bengkel Kapal & $\begin{array}{l}\text { Tidak Tersedia secara khusus, tempat } \\
\text { bengkel kapal biasanya memanfaatkan } \\
\text { lahan kosong di sekitar dermaga }\end{array}$ & $\begin{array}{l}\text { Disediakan, berupa sebuah ruang terbuka } \\
\text { dekat dengan dermaga dan dapat } \\
\text { dimanfaatkan sebagai tempat pendaratan } \\
\text { hasil tangkapan untuk pertama kali }\end{array}$ \\
\hline
\end{tabular}




\begin{tabular}{|l|l|l|}
\hline $\begin{array}{l}\text { Pasar dan } \\
\text { pelelangan ikan }\end{array}$ & $\begin{array}{l}\text { Tersedia pasar, dengan kondisi yang kurang } \\
\text { baik }\end{array}$ & $\begin{array}{l}\text { Kondisi pasar diperbaiki, dan ditambahkan } \\
\text { program food court untuk menunjang } \\
\text { penjualan pedagang seafood di pasar tersebut }\end{array}$ \\
\hline $\begin{array}{l}\text { Musholla dan } \\
\text { RPTRA }\end{array}$ & $\begin{array}{l}\text { Sudah tersedia, namun dalam jarak } \\
\text { tempuh yang jauh dari kawasan }\end{array}$ & $\begin{array}{l}\text { Menambahkan kembali fasilitas tersebut di } \\
\text { kawasan ini }\end{array}$ \\
\hline $\begin{array}{l}\text { Promenade / } \\
\text { Kawasan Tepian Air }\end{array}$ & Tidak tersedia & $\begin{array}{l}\text { Kawasan tepian air dikembangkan dan } \\
\text { dimanfaatkan sebagai sitting area, tenant } \\
\text { kudapan, view deck, dan promenade theater }\end{array}$ \\
\hline $\begin{array}{l}\text { Lapangan Terbuka/ } \\
\text { Ruang Terbuka }\end{array}$ & Tidak Tersedia & $\begin{array}{l}\text { Disediakan sebuah lapangan terbuka yang } \\
\text { dapat difungsikan sebagai event lawn }\end{array}$ \\
\hline
\end{tabular}

Sumber: Penulis, 2021

\section{KESIMPULAN DAN SARAN}

\section{Kesimpulan}

Dari desain hunian dan program yang penulis buat, dapat disimpulkan bahwa setiap program didasarkan pada perilaku dan kebutuhan nelayan (baik itu perbaikan ataupun penambahan program baru). Serta perbaikan atau penambahan fasilitas kawasan Kampung Nelayan,Kalibaru, baik berupa tatanan kawasan, bentuk massa, material bangunan, penyediaan sumber air bersih, rumah ibadah, RPTRA, dermaga, bengkel kapal,pasar ikan, pelelangan ikan, area penjemuran ikan dan ruang terbuka. Hal ini bertujuan untuk meningkatkan kualitas hidup nelayan di kawasan Kampung Nelayan Kalibaru.

Proyek ini dirancang untuk dapat menjadi contoh pengembangan atau redesign Kawasan Kampung Nelayan dengan berbasis pada pendekatan arsitektur perilaku yang dapat memudahkan aktivitas sehari hari nelayan tanpa menghilangkan perilaku sehari hari yang sudah terbentuk di Kawasan kampung nelayan yang sudah ada.

Dengan pendekatan arsitektur perilaku sebagai metode perancangan diharapkan proyek ini dapat menjadi sebuah hunian bagi nelayan yang sesuai dengan karakteristik mereka. Diharapkan proyek ini dapat menjawab beberapa permasalahan yang ada di Kawasan Kampung Nelayan, Kalibaru dan dapat menjadi sebuah percontohan bagi hunian vertikal untuk nelayan yang berdasarkan pada perilaku yang terbentuk dari setiap lapis kehidupan nelayan . Melalui proyek ini diharapkan kawasan kampung nelayan ini menjadi sebuah hunian yang liveable dan dapat dihuni dari generasi ke generasi.

\section{Saran}

Berdasarkan penelitian ini maka didapatkan saran yang dapat dilakukan untuk penelitian selanjutnya yang serupa adalah dalam proses revitalisasi sebuah kampung nelayan dapat menggunakan pendekatan arsitektur perilaku dalam mengolah data. Pendekatan arsitektur perilaku tentunya dilakukan berdasarkan kepada lokalitas kawasan yang akan menjadi obyek dalam penelitian. Pada penelitian ini hasil desain yang didapat berdasarkan perilaku dan lokalitas kawasan Kampung Nelayan Kalibaru, sehingga pada hasil dari penelitian lain dengan lokasi yang berbeda juga akan menghasilkan hasil yang berbeda. Perbedaan hasil ini terjadi dikarenakan perbedaan perilaku, lokalitas (termasuk didalamnya adat, suku, agama, kondisi exciting, dll.) yang juga berbeda pada setiap kawasan.

Saran lainnya yang dapat diberikan adalah dapat melakukan pengamatan perilaku secara lebih mendalam. Karena penelitian ini dilakukan di masa pandemi, sehingga pengamatan perilaku hanya di dapat dari berbagai literatur. Untuk penelitian selanjutnya diharapkan dapat melakukan pengamatan secara langsung perilaku pada berbagai waktu, sehingga perilaku yang di dapat bukan sekedar sampling dan dapat benar benar merasakan perilaku subjek di kawasan yang akan di revitalisasi 


\section{REFERENSI}

Agustina, Y., Purwantiasning, A. W., \& Prayogi, L. (2018). Konsep Perilaku Pada Penataan Kawasan Zona 4 Pekojan Kota Tua Jakarta. Jurnal Arsitekttur Purwarupa, 84.

Arinta, R. (2015). Revitalisasi Kawasan Pusaka Kota Lama Semarang. Yogyakarta: Tesis S2 Arsitektur UGM.

BPS Jakarta Utara. (2019). Penduduk, Laju Pertumbuhan Penduduk, Distribusi Persentase Penduduk Kepadatan Penduduk, Rasio Jenis Kelamin Penduduk Menurut Kelurahan dan Kecamatan di Kota Jakarta Utara 2019. Dipetik June 12, 2021, dari jakutkota.bps.go.id: https://jakutkota.bps.go.id/indicator/12/213/1/penduduk-lajupertumbuhan-penduduk-distribusi-persentase-penduduk-kepadatan-penduduk-rasiojenis-kelamin-penduduk-menurut-kelurahan-dan-kecamatan-di-kota-jakartautara.html

Hizmiakanza, A. S. (2018). Strategi Revitalisasi KAwasan Urban Heritage Banten Lama . Tesis , 28-29.

Karta, E. V., Tjung, L. J., \& Priyendiswara, A. B. (2019). Rencana Revitalisasi Kawasan Perbelanjaan Pasar Baru Dalam Rangka Meningkatkan Daya Tarik Sebagai Pusat Perbelanjaan Bersejarah. Jurnal Stupa, 2097.

Kostof, S. (1983). The City Ship. New York: The MIT Press,.

Marihot, F. (2017). Pemberdayaan oleh Aktor Non Negara Terhadap Masyarakat Nelayan di Kalibaru, Cilincing, Jakarta Utara. Tesis, 54-60.

Martokusumo, W. (2008). Mendaur Ulang Kota Tambang Sawahlunto: Beberapa Catatan tentang Pendekatan Konservasi dalam Revitalisasi. Makalah.

Melisa. (2020, 02 06). RISHA: Solusi Desain Rumah Tahan Gempa yang Minim Budget. Dipetik Juni 26, 2021, dari www.bramblefurniture.com: https://www.bramblefurniture.com/journal/konsep-rumah-risha/

Nur'Aini, R. D., Triharti, D., \& Rahman, T. N. (2015). Kajian Revitalisasi Arsitektural di Bantaran Kali Code Yogyakarta. Tugas Akhir , 5.

Pemprov DKI Jakarta. (2017). Investasi Air Bersih DKI Jakarta. Dipetik 06 12, 2021, dari ptsp.jakarta.go.id:

https://www.google.com/url?sa=i\&url=http\%3A\%2F\%2Fptsp.jakarta.go.id\%2Fpenana man_modal\%2Ffiles\%2Fsektor-investasi\%2FPotensi-Investasi-Sektor-Air-

Bersih.pdf\&psig=AOvVaw0InPvmyamkpYfwzmc5V5nn\&ust $=1628147934527000 \&$ sourc e=images\&cd=vfe\&ved=0CAsQjRxqFwoTCMDy6e3

PTSP DKI Jakarta. (2017). Investasi Air Bersih DKI Jakarta. Diambil kembali dari http://ptsp.jakarta.go.id/: http://ptsp.jakarta.go.id/penanaman_modal/files/sektorinvestasi/Potensi-Investasi-Sektor-Air-Bersih.pdf

Rahardjo. (2014). Pengantar Sosiologi Pedesaan dan Pertanian . Yogyakarta: Gadjah Mada University Press.

Tandali, Anthonius N. (2011). Arsitektur Berwawasan Perilaku (Behaviorisme). Media Matrasain , 55.

Usmagi, R. A. (2020, 06 29). Reklamasi Kawasan Ancol, Anies dan Pengembang Diminta Bangun 4000 Rusun Nelayan. Dipetik 07 01, 2021, dari Kompas.com: https://megapolitan.kompas.com/read/2020/06/29/15400561/reklamasi-kawasanancol-anies-dan-pengembang-diminta-bangun-4000-rusun 
